
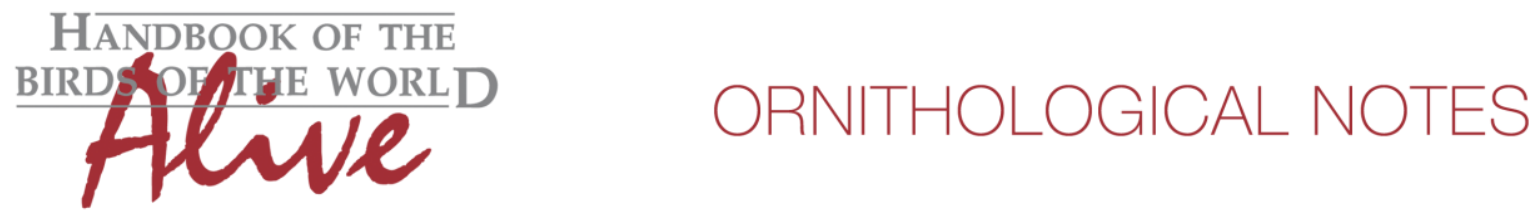

\title{
Notes on the vocalizations of Chirruping Wedgebill (Psophodes cristatus) and Chiming Wedgebill (Psophodes occidentalis)
}

Peter Boesman

In the following we briefly analyze and compare voice of the different races of Chirruping Wedgebill (Psophodes cristatus) and Chiming Wedgebill (Psophodes occidentalis). We also try to quantify the extent of any vocal differences using the criteria proposed by Tobias et al. (2010), as a support for taxonomic review. We have made use of sound recordings available on-line from Xeno Canto $(X C)$.

Song of both species is very different:

Chirruping Wedgebill : Repeated song phrase consists of 1 or 2 short introductory notes followed by a descending complex 'chirruping' note:

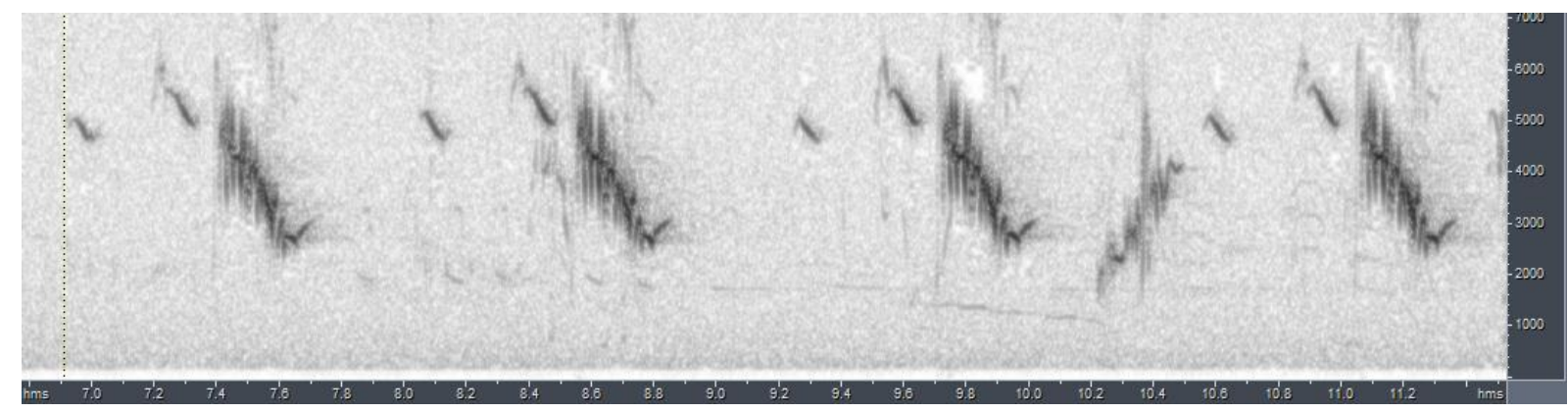

Measurements:

\# notes/phrase

longest note

max. freq.

$\min$. freq.

max. freq. range single note

total freq. range

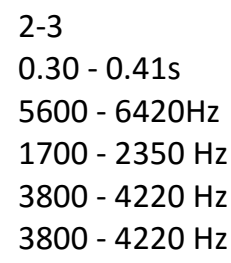

Chiming Wedgebill: Repeated song consists of some 3-5 short notes, typically gradually descending in pitch with the last note more gravelly or burry:

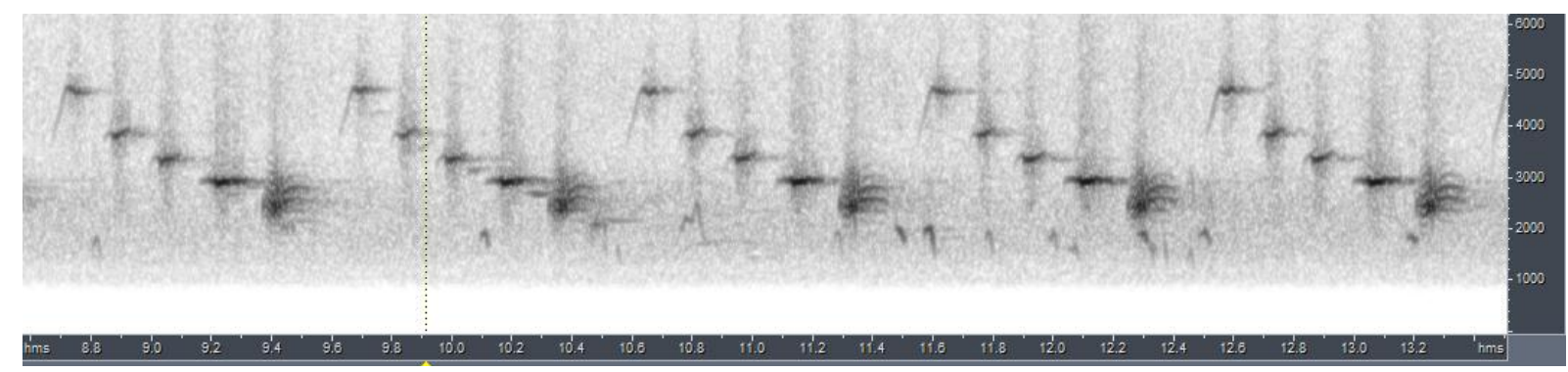



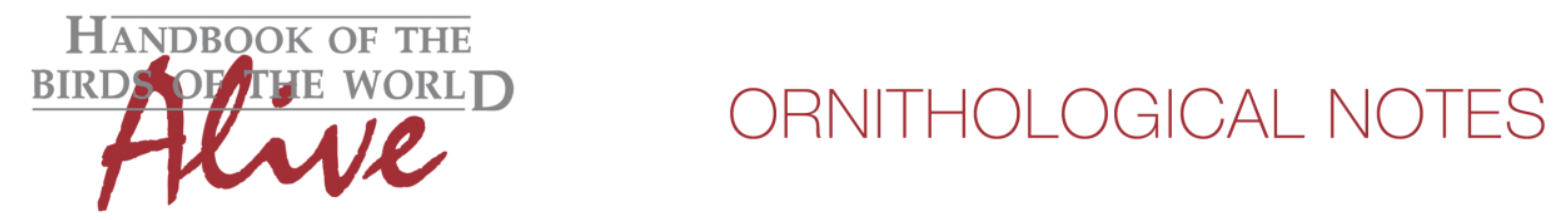

Several variations exist, but all are similar in structure, e.g.

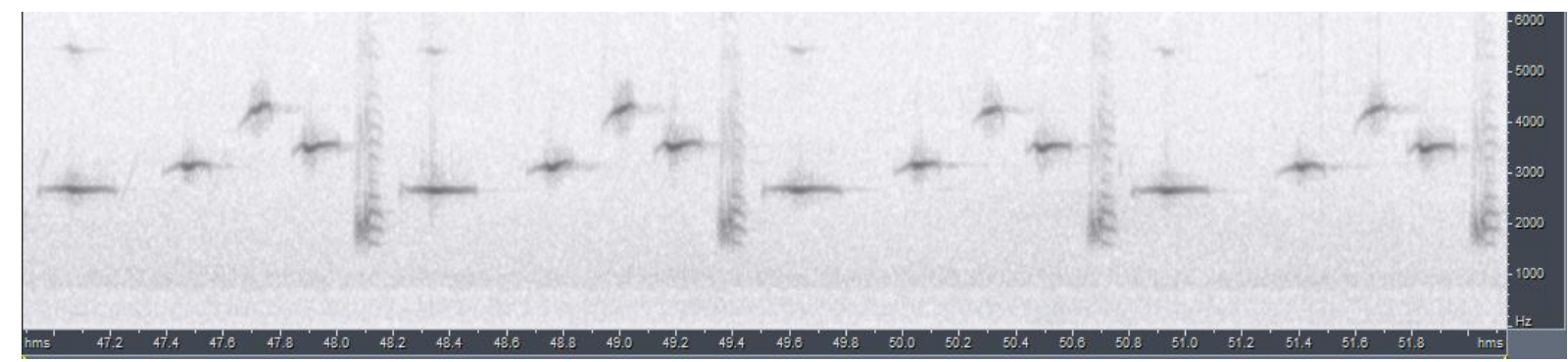

Measurements:

\# notes/phrase

4-5

longest note

$0.09-0.23 \mathrm{~s}$

max. freq.

$3760-4800 \mathrm{~Hz}$

min. freq.

$1270-2700 \mathrm{~Hz}$

max. freq. range single note

$150-1400 \mathrm{~Hz}$

total freq. range

$1900-3030 \mathrm{~Hz}$

Differences in song can be quantified by comparing basic sound parameters:

Chirruping Wedgebill has a song phrase consisting of less notes (score 3), and includes a long chirruping note which is much longer than any note of Chiming Wedgebill (score 3 ) and with a far higher frequency range (score 4). Furthermore, max. frequency and total frequency range in Chirruping Wedgebill are higher (score 3).

When applying Tobias criteria, this would lead to a total vocal score of 7.

Apparently, "in far NE South Australia there are some birds that appear to sing songs that are difficult to assign to one species or the other" (Graeme Chapman, see

http://www.graemechapman.com.au/library/viewphotos.php?c=552). I haven't found any recordings of that region to check this statement.

This note was finalized on 9th October 2015, using sound recordings available on-line at that moment. We would like to thank in particular the sound recordists: Matthias Feuersenger, Mark Harper, Nigel Jackett, Tom Tarrant and Fred Van Gessel.

\section{References}

Tobias, J.A., Seddon, N., Spottiswoode, C.N., Pilgrim, J.D., Fishpool, L.D.C. \& Collar, N.J. (2010). Quantitative criteria for species delimitation. Ibis 152(4): 724-746.

\section{Recommended citation}

Boesman, P. (2016). Notes on the vocalizations of Chirruping Wedgebill (Psophodes cristatus) and Chiming Wedgebill (Psophodes occidentalis). HBW Alive Ornithological Note 164. In: Handbook of the Birds of the World Alive. Lynx Edicions, Barcelona. (retrieved from http://www.hbw.com/node/932094 on 19 August 2016). 